\title{
GD04
}

\section{Benefits from Quantitative Interpretation Petrophysics (QI-PP)}

\author{
P.A. Abram* (SEIC- Shell), I. Sukhodoev (Sakhalin Energy Investment \\ Company Ltd.), A. Beresnev (Sakhalin Energy Investment Company Ltd.), \\ R. Nuriev (Sakhalin Energy Investment Company Ltd.), D. Khalmanova \\ (Sakhalin Energy Investment Company Ltd.), B. Blonk (Sakhalin Energy \\ Investment Company Ltd.) \& R. Simon (Sakhalin Energy Investment \\ Company Ltd.)
}

\section{SUMMARY}

Conclusions:

-The QI-PP technologies are employed in Sakhalin Energy for several purposes, e.g.:

o $\quad$ For seismic 4D monitoring in regards to changes in pressure (depletion/ injection), or in saturation or fluid types (water front, gas cap presence/extension). Therefore, the elastic rock properties were defined to predict the seismic response away from well control, and 1D and 2D synthetics were generated and studied for important reservoir settings.

o $\quad$ For fluid type appraisal, e.g. oil-water contacts in development targets or for thin oil rim detectability.

-Sakhalin Energy Petrophysicists are receiving training on the QI-PP-technologies by the in-house QI-PP specialist. That training is intended to allow the Petrophysicists to conduct QI-PP technologies by themselves in the future (co-assess the feasibility of upcoming 4D campaigns and support the 4Dinterpretation and de-risking of Sakhalin Energy's development targets).

Some results:

The geomechanical analysis on recently acquired cores in both the Lunskoye and Astokh assets allows defining how effective pressures alter the seismic velocities. These results will be included to support predicting the effects of pressure changes by injection and depletion on seismic data, quantitatively.

Recent QI-PP studies demonstrated that residual or migrating gas is present in the LUN aquifers and that the oil rim is seismically barely visible. 


\section{Introduction}

Exploration and production projects use seismic methods to derive and monitor rock properties and fluids. In order to employ these methods adequately it needs to be known how rock types, thicknesses, compaction, depletion and injection activities affect seismic data.

Quantitative Interpretation Petrophysics (QI-PP) can assess the impact of these factors on seismic data and find answers to, e.g., whether higher amplitudes at the crest of a structure result from a change in Net/Gross or from presence of low saturation gas, or whether changes in saturation due to depletion will affect the seismic AVO-character in a 4D-monitoring activity.

Sakhalin Energy acquired 4D data over the last decade to monitor water and gas movements, delineate reservoir connectivity and identifying future targets for oil and gas producers and water injectors. The recent 2015 vintage is currently being interpreted and early results are already impacting all three assets Piltun, Astokh and Lunskoye.

The technologies of QI-PP are being applied in Sakhalin Energy to support the interpretation of this 4D-data and also to appraise reservoir quality and fluids in undrilled areas of the three assets.

\section{Methods}

The electrical logs from selected Sakhalin Energy wells are being modified using the Gassmann fluid substitution to reflect different reservoir conditions. The effects of changes in pressure by depletion/injection and the fluid movement (gas and water) are modelled by convolving the seismic wavelet with corresponding logs and fluid data. The generated synthetic seismic for normal incidence and for AVO are then investigated for distinct recognisable features, e.g. amplitude changes or phase shifts.

Elastic rock trends are also defined to model the elastic properties away from well control, for example trends between seismic compressional to shear waves, or trends modelling compaction with depth. These trends are used as inputs for seismic 3D and 4D inversion studies.

\section{Results}

The QI-PP forward modelling from well logs (see Figure 1) has indicated challenging but possible interpretability of 4D data in regards to seismically illuminating the waterfront or gas cap extension in the Piltun asset. So far, the early results from the 4D difference maps look promising for Piltun.

The ongoing geomechanical analysis on recently acquired cores in both the Lunskoye and Astokh assets allows defining how effective pressures alter the seismic velocities. These results will be included in the QI-PP rock model to support predicting the effects of pressure changes by injection and depletion on seismic data, quantitatively.

The elastic rock properties for the Piltun and Astokh assets were defined. Core information like mineralogical composition or permeability allowed to discern and fine-tune these properties depending on reservoir facies types. The latter will support predicting from 4D-seismic the strong risks for gas and water movement from the highly permeable Superfacies/Uberfacies facies types.

Recent QI-PP studies in Lunskoye demonstrated that residual or migrating gas is present in the aquifers and that the oil rim is seismically barely visible. This is a topic of ongoing 4D interpretation.

\section{Conclusions}

- The QI-PP technologies are employed in Sakhalin Energy for several purposes, e.g.:

- For seismic 4D monitoring in regards to changes in pressure (depletion/ injection), or in saturation or fluid types (water front, gas cap presence/extension). Therefore, the elastic rock 
properties were defined to predict the seismic response away from well control, and 1D and 2D synthetic were generated and studied for important reservoir settings.

- For fluid type appraisal, e.g. oil-water contacts in development targets or for thin oil rim detectability.

- Sakhalin Energy Petrophysicists are receiving training on the QI-PP-technologies by the in-house QI-PP specialist. That training is intended to allow the Petrophysicists to conduct QI-PP technologies by themselves in the future. Their QI-PP results will be required to co-assess the feasibility of upcoming 4D campaigns (possibly for all three fields in 2018), and support the 4Dinterpretation and de-risking of Sakhalin Energy's development targets.

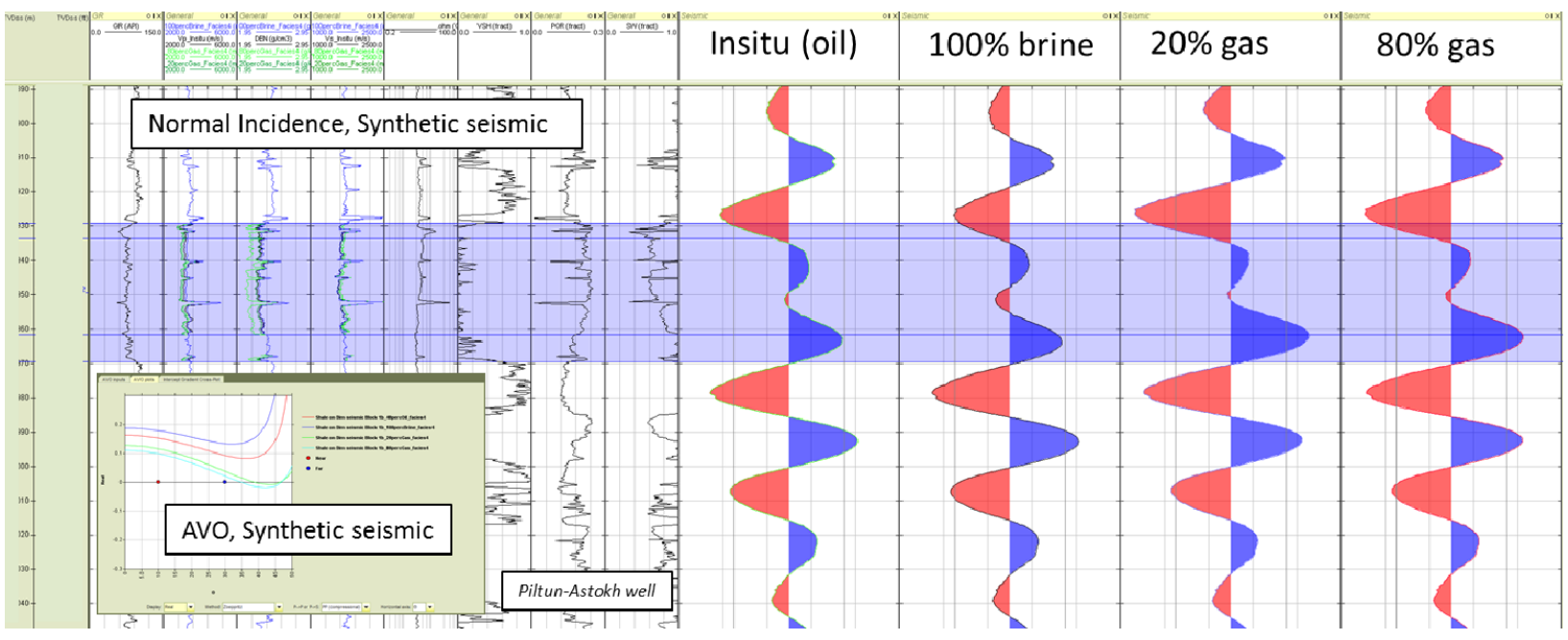

Figure 1 Modelled seismic response to changes in fluid type: Changes in fluid types and saturation go along with seismic amplitude changes. This and other results from QI-PP technologies are/were used to determine oil rim detectability in seismic for Lunskoye, to identify fluid types in appraisal targets (e.g. Piltun Block 1b) or to assess the benefit of $4 D$-activities, e.g. visibility of possible gas cap extension due to depletion in Piltun-Astokh. 